\title{
The Concept of Intelligence and Its Role in
}

\section{Lifelong Learning and Success}

\author{
Robert J. Sternberg \\ Yale University
}

This article proposes a definition of intelligence as comprising the mental abilities necessary for adaptation to, as well as selection and shaping of, any environmental context. According to this definition, although the behavior that is labeled as intelligent may differ from 1 environmental context to another, the mental processes underlying this behavior do not. An individual's ability to apply these processes may differ from 1 context to another, however. The abilities are applied to achieve external correspondence to the world and internal coherence among various knowledge and belief structures. The relevance of the definition for understanding current theories, testing in the field of intelligence, as well as for understanding the role of intelligence in lifelong learning is discussed.

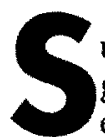
uppose some psychologists wrote a book suggesting that green people are better educated, more economically successful, and more socially adept than purple people, largely because the green people are more intelligent than the purple ones. Such comparisons are, in fact, made, although the groups that are compared in the real world are not, typically, either green or purple. Before we draw any conclusions about either group of people, we may wish to consider exactly what is meant by intelligence.

\section{Defining the Concept of Intelligence}

There is no lack of definitions of intelligence (see, e.g., "Intelligence and Its Measurement: A Symposium," 1921; Neisser, 1979; Sternberg \& Detterman, 1986). In the 1921 survey of scholars in the field of intelligence, the most common elements in the proposed definitions were (a) higher level abilities (such as abstract reasoning, mental representation, problem solving, and decision making), (b) ability to learn, and (c) adaptation to meet the demands of the environment effectively. In the 1986 survey, the most common elements were (a) higher level abilities, (b) that which is valued by culture, and (c) executive processes.

An important theme in many definitions over the years, including those of the fathers of intelligence testing - Binet and Simon (1905/1916) and Wechsler (1939, 1958) - has been that of adaptation, a theme that, arguably, also makes sense in an evolutionary context (Barkow, Cosmides, \& Toobey, 1992; Buss, 1995; Jerison, 1982;
Wright, 1994). However, human beings do not just adapt to the environment: They shape their environment and, at times, select a new environment.

I propose, here, the following definition: Intelligence comprises the mental abilities necessary for adaptation to, as well as shaping and selection of, any environmental context. According to this definition, intelligence is not just reactive to the environment but also active in forming it. It offers people an opportunity to respond flexibly to challenging situations. Because the landscape of an environmental context changes over time, adequate adaptation, shaping, and selection involve a process of lifelong learning, one that starts in infancy and continues throughout the life span.

To shape the environment or, ultimately, decide to select a new one, an individual generally has to first learn how to adapt to the environment he or she is in. Only then is the individual able to decide which features of this environment to accept and which to reject. Intelligence, in this view, is a key to lifelong learning.

At all points in life, intelligence serves at least two broad functions: to establish (a) external correspondence and (b) internal coherence. People achieve external correspondence when their beliefs about a phenomenon are veridical - when they understand that phenomenon. For example, if we understand that if we touch a very hot object, we may burn ourselves, we have achieved some degree of external correspondence. People achieve internal coherence when their knowledge and beliefs about a phenomenon are well and consistently connected, such that they do not contradict each other. For example, if we understand fire as being hot, dangerous, used for cooking, and so on, our beliefs have high internal coherence. They fit together well and do not contradict each other.

Editor's note. John Kihlstrom served as action editor for this article.

Author's note. The work described in this article was supported by a government grant under the Javits Act Program (Grant No R206R50001) as administered by the Office of Educational Research and Improvement, U.S. Department of Education. Grantees undertaking such projects are encouraged to express freely their professional judgment. This article, therefore, does not necessarily represent the positions or the policies of the U.S. government, and no official endorsement should be inferred.

Correspondence concerning this article should be addressed to Robert J. Sternberg, Department of Psychology, Yale University, Box 208205 , New Haven, CT $06520-8205$. Electronic mail may be sent via Internet to robert.sternberg@yale.edu. 
Internal coherence can achieve more sophisticated forms, as when individuals realize that much of people's understanding of phenomena develops dialectically (Hegel, 1807/1931; Labouvie-Vief, 1982; Pascual-Leone, 1984, 1987; Sternberg, 1995b). Ideas that seem incompatible with, and even contradicting of, each othera thesis and antithesis-may prove to be compatible through a synthesis either at a higher level of abstraction or when seen from a different point of view.

According to this view, individuals test the world much as a test tests intelligence. People's beliefs have some measure of validity (external correspondence) and reliability (internal coherence). A more intelligent, adaptive person has achieved a higher degree of external correspondence and internal coherence in his or her knowledge base and belief structures. People think unintelligently to the extent to which they make errors in achieving external correspondence or internal coherence. For example, in believing in the gambler's fallacy, a person fails in achieving external correspondence; in touching a hot stove despite knowledge of the danger of doing so, a person fails in achieving internal coherence.

\section{Defining Intelligence}

\section{Environmental Context}

Starting at the end of the definition, I define intelligence as relevant to any environmental context. This context has physical, biological, and cultural aspects, which may interact. For example, cultural artifacts (from prescription glasses to computers) can facilitate adaptation to the environment. But the same artifact (e.g., computers) that makes the environment more friendly for some individuals may render it more hostile for others who are unable or unwilling to adjust to the artifact.

Although people usually think in terms of adaptation to the environmental context, shaping and selection of environments can be important too. The intelligent person, having come to understand the environmental context, may decide to reject aspects of it and try either to change the environmental context or, ultimately, to find another. Many of the most creatively and practically intelligent people - those who have left a lasting impact on others as well as themselves - are people who have changed the environment, not just for themselves but for others as well (Sternberg, 1985a, 1990, 1996b; Sternberg \& Lubart, 1995, 1996). Mozart, Einstein, Churchill, and Picasso are just four of many names that might come to mind, but many who have made some kind of lasting impact may have left as their legacy their impact only on family and friends, not an impact on the history books.

In defining intelligence, researchers need to carefully distinguish among intelligence, intelligent behavior, and tested intelligence (see also Hebb, 1949). Confusions among these three concepts have resulted, perhaps, in confusions regarding the nature of intelligence.
What constitutes intelligent behavior may differ from one environmental context to another, even radically. For example, Cole, Gay, Glick, and Sharp (1971) pointed out that the same sorting behavior that was considered intelligent among Western people (i.e., sorting by taxonomic category) was considered foolish among members of the Kpelle tribe, who valued a different kind of sorting behavior-sorting by functional category. Heath (1983) and Okagaki and Sternberg (1991) have shown how different ethnic groups in the United States may have different conceptions of what constitutes intelligent behavior, and I (1985b) have shown how different professional groups may even have different conceptions of intelligent behavior on the part of members of those groups.

Each of the examples pertaining to intelligence refers to differences in what constitutes intelligent behavior in one group versus another. But the mental processes necessary to generate these diverse behaviors may actually be the same. Intelligence, I argue, has a common core of mental processes that manifests itself behaviorally in different ways in different contexts (Sternberg, 1985a, 1988, 1996b).

For example, the ability to learn is important in any environmental context, but what is learned, both in terms of declarative and procedural knowledge, may differ radically from one environmental context to another. Thus, both the average American and the average Kpelle need to learn to sort objects, but the learned kinds of rules, according to which they sort in various situations (what constitutes intelligent behavior), may differ. As people pass through their lives and pass from being novices to experts in a variety of domains (Chi, Glaser, \& Farr, 1988), the rules that are considered acceptable may change.

The distinction between intelligence and intelligent behavior is important, in part, because there has been so much confusion in the literature on intelligence regarding contextual generality versus specificity of intelligence. To what extent is something that is intelligent in one cultural or subcultural context intelligent in another (Sternberg, 1985a)? Much of the confusion may stem from the confounding of intelligent thinking with intelligent behavior. Because the same mental processes may give rise to very different behaviors in different kinds of environmental contexts, tasks, and specific situations, the processes but not the behaviors may be common across environmental contexts.

Among the core mental processes that may be key in any culture or other environmental context (Sternberg, 1985a) are (a) recognizing the existence of the problem, (b) defining the nature of the problem, (c) constructing a strategy to solve the problem, (d) mentally representing information about the problem, (e) allocating mental resources in solving the problem, (f) monitoring one's solution to the problem, and (g) evaluating one's solution to the problem. Although the mental processes are common across environmental contexts, people's ability, motivation, or decision to apply these processes across contexts may not be equal. Thus, people may not appear equally 
intelligent behaviorally in all settings. There are several reasons why discrepancies may arise.

First, consider the question of ability to apply mental processes. Mental processes operate on mental representations, and as Anderson (1983) pointed out, it is difficult to isolate mental processes from the mental representations on which they operate. Thus, someone might make good inferences in the verbal domain, but not in the quantitative domain. Simply measuring an abstract inferential processing ability would be inadequate, because the person's ability in inferential processing could differ across the verbal and quantitative or other representational domains (Sternberg \& Gardner, 1983). Someone else might make good inferences in the quantitative but not the figural domain. The result of these differences is some amount of domain specificity in intellectual functioning.

Second, consider the question of motivation. Individuals may be differentially motivated to apply their mental processes in different domains. Someone might have the ability to do equally well in linguistic or mathematical work but simply decide that one or both of these activities are not interesting. Or, lacking self-efficacy in a domain (Bandura, 1977), the individual may be convinced by others or convince him- or herself that an ability is lacking and, therefore, not take steps to display or even develop it. Some of our greatest potential poets, for example, may never have tried to write even one line of poetry. The individual thus does not act in a way that manifests intelligence as it is evaluated in that domain.

Third, consider the question of the decision to apply mental processes to behavior. Individuals may use mental processes to reach a conclusion as to what is valued in the context in which they are operating and then decide, for moral or other reasons, not to act on the conclusion they reach. For example, a society such as Nazi Germany may value immoral behavior, but not everyone will decide to act immorally, despite the knowledge that such behavior is valued by the society.

All of these examples point to a fundamental fact about the assessment of intelligence: Mental processes are always evaluated through behavior of some kind. We draw conclusions about these processes from behavior, but these conclusions are not always justified. For example, poor performance on an intelligence test might reflect poor processing of information but also might reflect test anxiety, lack of motivation, inattention, or any number of other variables.

\section{Necessity for Purposeful Adaptation to or Shaping or Selection of Any Environmental Confext}

It is difficult to imagine any environmental context in which core mental processes such as recognizing the existence of a problem or allocating mental resources, as expressed through different domains of human endeavor, would not be necessary. The Kpelle may define a sorting problem differently from Westerners, but members of both groups have to define the problem. We need all of these mental processes and mental representations on which they can act, in any domain and at any level, at some time.

Even infants recognize, at some level, the existence of a problem, such as hunger, and engage in goal-directed activities to acquire and allocate the resources they need. Over time, they learn (through various kinds of experiences) what kinds of behavior will help them better attain the resources they want and achieve other goals. Presumably, mental abilities develop as a result of the interaction of genes with experiences that arise through the environment.

Mental processes such as these, as well as the representations on which they act, may be devoted to behavior that makes an individual look intelligent, as in the typical school-based situation, or they may be devoted to behavior that makes an individual look unintelligent. For example, members of an adolescent or other peer group may decide that it is preferable to look academically stupid in school and devote exactly the same mental resources to looking academically stupid (recognizing the existence of a problem, defining it, setting up a strategy, etc.) that other students are devoting to looking intelligent (a concept that McDermott, 1974, referred to as achieved failure). Or in a repressive society in which the leader has decided to eliminate intellectuals (there have been many), such as Idi Amin of Uganda or Pol Pot of Cambodia, intelligent people may go and have gone out of their way to hide their intelligence in order to survive. Indeed, it may take a considerable amount of intelligence to successfully hide one's intelligence. Once again, mental representation and processing, rather than behavior, provide the important diagnostic cues for intelligence.

This same logic applies to the distinction between intelligence and tested intelligence. Members of a peer group may decide to be indifferent to and, thus, look stupid on a test to affirm their solidarity with their group. Or they may disidentify with the kinds of behavior valued in these tests (Steele \& Aronson, 1995), so that they no longer view their score on the test as relevant to their identity or their self-esteem. Or they may simply be test anxious. In each case, socially valued intelligence test performance can suffer.

To the extent that the same representations and processes are at work in school, on the job, or on the test, the test will appear statistically valid, but only because both predictor and criterion share the same performancesuppressive mental processes, such as disidentification. In other words, the same processes may lead to poor intelligence test scores and school grades, giving the appearance of a valid test, when in fact the individual could do much better in both if he or she chose to or was successfully encouraged to do so. The bottom line is that one can appear intelligent because of predictors sharing the same features as criteria, both of which reflect a culture's values. More generally, we have created a "closed system" in which a relatively narrow band of abilities leads to success or failure on both academic predictors and the criteria they were designed to predict.

Because American society places a high value on 
tested intelligence and the memory and analytical abilities underlying it, high levels of tested intelligence have become important to the attainment of various forms of success in the society. For example, high American College Test or Scholastic Assessment Test scores are often essential for college admissions, and, later, high scores on other tests become important for admission to competitive law schools, medical schools, business schools, and so on. So heavily are these tests used that we may confuse what is necessary for adaptation-intelligence-with what is not really necessary. For example, many people have been able to attain their goals in life or even in school, even in difficult graduate programs (Sternberg \& Williams, 1997), in the absence of high test scores. But society has created a social system that has made the attainment of such success difficult for low scorers, simply because of the heavy use of the tests in selection and placement decisions.

Many of those with lower test scores, including some with high levels of creative and practical intellectual abilities (Sternberg, 1996a), simply are not given the chance to show whether they can succeed, because they are denied admission to the access routes to many kinds of success that society, at least, values. Scholars such as Herrnstein and Murray (1994) have gone on to confuse a U.S.-society-invented near necessity (high tested intelligence) with a true necessity for adaptation to the U.S. environmental context (high intelligence). In essence, they believe they have discovered a natural law that is, in fact, a societal invention.

The difference between the two kinds of elements is readily seen. Suppose admissions officers decided that, instead of high test scores, they wished to use height as a basis for college and graduate admissions (see Sternberg, 1995a, 1996b). In its favor, this criterion can be very reliably measured, is not susceptible to change through preparatory books and courses, and is relatively difficult to fake. Few if any people would view height as tantamount to intelligence; indeed, most of us have known people whom we would consider to be tall but unintelligent, as well as people we would consider to be short but intelligent. Using height as a basis for various kinds of selection decisions should not sound too strange, however, as the data indicate that we already use it. Most winning presidential candidates tend to be taller than their opponents.

Under the new system, within a short time, access routes to educational, social, and economic opportunities would start to depend heavily on height. Ultimately, lawyers, doctors, college professors, and others in higher prestige jobs would be quite tall, whereas those closer to the bottom of the educational, social, or economic scale would be quite short. Presumably, we would not want to view this correlation between height and opportunity either as necessary or as representing a new kind of "tallness intelligence." Nor should we view the caste systems used in many present and past societies-systems that propel members of the high social castes to the top of the society and of the low social castes to the bottomas representing any level of caste-based intelligence.

Thus, I am suggesting that the criteria for identifying an ability as "intelligence" inhere in the (a) necessity of (b) mental ability for (c) adaptation in, or shaping or selection of, (d) any environmental context, not just in any one particular environmental context. Defining problems, setting up strategies to solve problems, and allocating resources, for example, are all abilities (which may be nonindependent) that would be necessary for adaptation anywhere. Indeed, people would not survive long if they did not, for example, recognize a problem when a predator (human or nonhuman) was about to attack, or when they exposed themselves to the likelihood of grave physical harm. These criteria seem useful and possibly even nonarbitrary, because they follow directly from the definition of intelligence as comprising the abilities necessary for adaptation, shaping, and selection.

Individuals could, of course, choose instead to define intelligence as comprising mental abilities that are merely relevant or useful for contextual adaptation rather than necessary. But the necessity criterion combined with the universality criterion are important to avoid both proliferation and idiosyncrasy. For example, one culture might decide that members of one ethnic group or another should necessarily be exterminated, or as it is now euphemistically called, "ethnically cleansed." Perhaps all members of this group will even be perceived as mentally incompetent. Tests may even be arranged to certify their incompetence. People would probably not want ethnicgroup membership to become part of a definition of intelligence just because one particular culture decides that certain memberships but not others meet their criteria for adaptivity.

\section{Mental Abilities}

Why should individuals limit themselves to mental abilities? Because there are abilities, such as the ability to see, hear, smell, or taste, that might otherwise come under the rubric of intelligence. Why shouldn't they? These physical (rather than mental) abilities fail the necessity test: They may be useful for contextual adaptation, but they are not necessary, at least universally. People can, for example, lose their sense of smell or even their vision but adapt well in many kinds of contextual settings and roles. What is probably necessary for adaptation is the ability to form mental representations, which may be quite similar to those of people who see, that are based on information gleaned from one's senses that are functioning. Whereas the ability to see is not essential for intelligence, however, the loss of the ability to plan one's actions or mentally represent them will lead to poor contextual adaptation in any setting.

\section{Alternative Conceptions of Intelligence}

Where does our definition of intelligence leave the field with respect to the various kinds of intelligence that some psychologists are now proposing, some of which involve abilities that seem to go beyond the "mental"? Consider, 
for example, a construct such as emotional intelligence (Goleman, 1995; Salovey \& Mayer, 1990). A priori, there is no reason not to posit the abilities to understand and regulate emotions as a kind of intelligence. What researchers would need to do is to determine whether these abilities pass the tests for a type of intelligence. The abilities would seem to be universal, although, again, their behavioral manifestations might differ somewhat from one environmental context to another. Present data suggest a separation of these abilities from conventional kinds of psychometrically measured intelligence (Mayer \& Geher, 1996), although further study is needed. What remains to be shown is whether these abilities are necessary for adaptation to the environmental context, a demonstration that, as for any other kind of intelligence, requires a somewhat extensive construct validation that has yet fully to be conducted.

Various abilities that have in fact been posited as relevant to intelligence in the past do not pass the tests for intelligence described here, including musical and bodily kinesthetic intelligence (Gardner, 1983). In particular, these abilities are not universally necessary for adaptation to, selection of, or shaping of environments, although they might be necessary in particular cultural contexts. (Of course, other criteria can be and have been proposed to identify what constitutes intelligence [e.g., Gardner, 19831). Thus, these abilities do not meet the criteria set out here, although they meet other criteria set out by Gardner (1983). In contrast, skills such as planning or evaluating would be necessary in any environment and evolutionarily serve a kind of adaptive function for survival that, say, musical abilities do not.

Practical intelligence (Sternberg, 1985a; Sternberg \& Wagner, 1986, 1993; Sternberg, Wagner, \& Okagaki, 1993) has been studied over a somewhat longer period of time and seems to show evidence of the kind of construct validity necessary to label it as a valid kind of intelligence. In particular, practical intelligence is relatively independent of (analytical) intelligence as measured by conventional tests, and it predicts various kinds of school and job performances over and above the prediction provided by other kinds of existing tests (Sternberg, Wagner, Williams, \& Horvath, 1995). In school, our research has shown that practical intelligence can contribute to the prediction of grades and that when students who rate high in practical intelligence are taught in a way that lets them capitalize on this form of intelligence, they perform better than when they are taught in standard ways that do not permit such capitalization (Sternberg \& Clinkenbeard, 1995; Sternberg, Ferrari, Clinkenbeard, \& Grigorenko, 1996).

In our own work to date (Lubart \& Sternberg, 1995; Sternberg \& Lubart, 1992, 1995, 1996), we have been unable to attain the same kind of separation of creative intelligence from analytical intelligence that we have attained for practical intelligence. Moreover, the universal necessity of creative intelligence is probably less clear at this point. Thus, creative intelligence perhaps remains only as a "candidate intelligence," rather than as one whose existence has been clearly demonstrated.

Yet another kind of intelligence is social intelligence (e.g., Cantor \& Kihlstrom, 1987; Ford \& Tisak, 1983; Keating, 1978; Sternberg \& Smith, 1985). This construct has been conceptualized in different ways. For example, Cantor and Kihlstrom (1987) emphasized the possession of knowledge and beliefs and the repertoire of skills that a person uses to negotiate social interactions. Sternberg and Smith (1985) emphasized certain communicational skills, especially nonverbal ones. Except, perhaps, for utter hermits, people live in a social world, where the absence of social-intellectual skills would be a severe limitation on a person's ability to successfully adapt to their environment. Learning to adapt to the environment is a key to lifelong success. But do all students get an equal opportunity to learn to adapt?

Finally, of course, there is the kind of more academically oriented intelligence that is measured by various kinds of conventional tests. Myriad studies have shown the importance of academic intelligence in academic work and, to some extent, in life success (see Carroll, 1993; Herrnstein \& Murray, 1994; Hunt, 1995; Schmidt \& Hunter, 1993). This kind of analytical intelligence is probably measured reasonably well but imperfectly for many people acculturated to the demands of such tests. It is needed for remembering information, for critiquing it, and for deciding on its value. People need to recognize, however, that success in almost any job requires creative and practical skills (as well as noncognitive attributes) that conventional intelligence tests do not measure (Sternberg, 1996b).

\section{The Concept of Intelligence in Relation to School and Lifelong Learning}

The ability to learn has historically occupied a central place in definitions of intelligence; indeed, it is hard to find any definition or theory that would not include this ability (which is multifaceted) as an aspect of intelligence. But the ability to learn provides a good case study of both the prospects and the pitfalls that people encounter in the study of intelligence.

Early research on the relation between learning and intelligence surprisingly led to many weak or even negative findings (see review by Estes, 1982). At face value, this situation might seem rather absurd - how could the ability to learn not be related to intelligence? If it were not found to be related, then one might conclude, at least tentatively, that there was something wrong with the tests of learning, the tests of intelligence, or both.

Later research showed that there was definitely something wrong with the tests of learning, at least as measures of intelligence and quite possibly as measures of realistic learning. In particular, the kinds of simple laboratory-based learning used in the early tests (such as serial recall of digits, which is still found on tests of intelligence such as the Wechsler) were not the best predictors of school or other forms of achievement (Campione \& Brown, 1990; see also Neisser, 1982). If, or as, 
individuals expand the kinds of abilities that they care about for learning in the school or job context (Gardner, 1983, 1993; Sternberg, 1994, 1996b), they may find that they need to expand the ways in which intelligence is tested to predict that learning.

Researchers commonly agree that fluid intelligence as psychometrically tested often decreases in old age and that crystallized intelligence may continue to increase or, at least, that it may avoid decline (see Horn, 1986, 1994; Salthouse, 1996). To the extent that researchers accept the definition of intelligence proposed in this article, what happens to intelligence can be seen only in terms of the abilities relevant to the culturally based tasks that a person confronts at different points in the life span. It is for this reason that the mechanism of selective optimization with compensation proposed by Baltes and his colleagues (e.g., Baltes, Dittmann-Kohli, \& Dixon, 1984) may be so important for understanding intelligence. According to Baltes et al., as people age, they learn to make good use of the abilities they have that remain intact, at the same time that they learn to compensate for the abilities they are losing. In general, what is needed for learning and functioning may differ at varying points in the life span.

My colleagues and I, in our own research (Sternberg, 1997; Sternberg \& Clinkenbeard, 1995; Sternberg et al., 1996), have found that a broader conception of the learning and thinking abilities that are underlying human intelligence can make a constructive difference in the context of schooling. In this conception, students are given more flexibility to use their mental abilities to adapt to and shape their environmental contexts. Theory-in this case, the triarchic theory of human intelligence (Sternberg, 1985a)-is put into practice in a way that potentially might benefit all students.

My colleagues and I selected a set of 199 high school students on the basis of their scores on the Sternberg Triarchic Abilities Test (Sternberg, 1993), a research test used to measure analytical, creative, and practical abilities as measured by three kinds of multiple-choice items - verbal, quantitative, and figural - as well as three essay items, with each one focusing on either analytical, creative, or practical abilities. As examples, analytical abilities are measured verbally by having individuals' learn meanings of words in context, or through verbal essays by individuals' writing about the comparative advantages and disadvantages of armed security guards in schools; creative abilities are measured quantitatively by individuals' performing novel numerical operations; and practical abilities are measured figurally by individuals' planning routes using maps and diagrams.

Analytical, creative, and practical scores on this test are moderately intercorrelated when observed scores are used but only weakly correlated after controlling for method variance (multiple choice vs. essay). In the research of my colleagues and I, the test showed no substantial General factor, presumably because it measures a broader range of abilities than does a conventional test. The analytical section showed the highest correlations with conventional psychometric ability tests, followed by the creative section, and then the practical section, which was only weakly correlated with the conventional tests. Students were identified either as (a) high-analytical, (b) high-creative, (c) high-practical, (d) high in all three abilities, or (e) low in all three abilities.

The students were then placed in sections of a college-level introductory psychology course that emphasized primarily (a) memory-based learning and thinking, (b) analytical learning and thinking, (c) creative learning and thinking, or (d) practical learning and thinking. For example, in a memory-oriented course, individuals might be tested on the main tenets of psychodynamic and cognitive theories of depression; in an analytically oriented course, they might be asked to compare and contrast the theories; in a creatively oriented course, to generate their own theory; and in a practically oriented course, to apply an existing theory to help a depressed friend.

All students were then evaluated for (a) memorybased achievement, (b) analytically based achievement, (c) creatively based achievement, and (d) practically based achievement. For example, students might have been asked to remember the main details of an experiment (memory), analyze the strengths and weaknesses of the experiment (analytical), generate their own experiment (creative), or apply the results of an experiment to their lives (practical). Evaluations included homework assignments, examinations (including both multiple-choice and essay items), and an independent project, all of which were assessed for all four kinds of achievements.

The design was therefore a 5 (ability groupings; between subjects) $\times 4$ (methods of instruction; between subjects) $\times 4$ (kinds of assessment of instruction; within subjects) interaction. The critical manipulation was that students were randomly placed into instructional groups so that they were either matched (e.g., a high-creative student in instruction that emphasized creative learning and thinking) or mismatched (e.g., a high-creative student in instruction that emphasized memory-based learning and thinking) to their ability grouping.

It is important to note that although instructional conditions emphasized one kind of thinking and learning or another, they were not "pure." The text (Sternberg, 1995b) contained instruction that fostered memorybased, analytical, creative, and practical learning and thinking. Moreover, all students received the same morning lectures. The experimental manipulation occurred in the afternoon, when students were assigned to sections that emphasized only one kind of instruction or another. In the ideal classroom, it is important not only to help students capitalize on strengths but also to compensate for and remediate weaknesses. All students need a balance of all kinds of instruction and assessment.

We found that those students who received instruction that better matched their ability profile performed significantly and substantially better than did those who were mismatched. Moreover, multiple regression analysis revealed that prediction of course performance was significantly improved by considering creative and practical in addition to analytical abilities. An interesting and un- 
expected finding was that students who identified as high in creative or practical abilities were substantially more ethnically and socioeconomically diverse than were students identified as high in the more conventionally measured analytical abilities. Narrow ability testing may thus result in underrepresentation of certain groups in the intellectual talent pools identified by such tests.

In summary, when students learn in a way that lets them capitalize on their strengths as well as compensate for and remediate weaknesses, they perform better than when they are taught in standard ways. The proposed diversification of instruction as well as assessment means that students need to adapt to instruction that is not compatible with their profile of abilities, but they also can shape their learning environments to best capitalize on the strengths in their ability profiles. Moreover, all students potentially learn better when they are able to multiply encode subject matter taught to them in a variety of ways. In recent research (Sternberg, Torff, \& Grigorenko, 1997), we have found that both third- and eighth-grade students who are taught social studies or science triarchically outperform students who are taught traditionally or for critical thinking, not only on performance-based tests but on multiple-choice, fact-based tests as well. From an educational standpoint, people will better identify intellectual talent when they start to think of intellectual talent in broader terms.

The triarchic theory provides one way of enhancing students' abilities to adapt to and shape their environmental contexts and, ultimately, to select the environmental context in which they will make their career or other contribution, but it is certainly not the only theory that might be used. Other theories might also be shown to provide such flexibility (e.g., Carroll, 1993; Gardner, 1983).

These results have broad implications for lifelong accomplishment because our current, narrower conceptualizations of abilities create a closed system in which a narrow subset of talented students - those high in memory and analytical abilities - are benefited at all points in the system. They do better on ability tests, learn better in courses where the instruction is geared to them, and then perform better on achievement tests that measure these restricted kinds of learning. The appearance is thus created of highly valid ability tests that predict to highly valid achievement tests, when in fact the validity is created by having the same bias in the criterion as in the predictor. Students with creative and practical abilities are essentially "iced out" of the system, because at no point are they much allowed to let their abilities shine through and help them perform better in school. In effect, they become the "green" or "purple" people who appear to be intellectually lacking but perhaps because the conventional standards for evaluating abilities are lacking.

The result is that career paths may be barred to intellectually talented individuals who potentially could stand to make great contributions. Budding psychologists with outstanding creative or practical abilities-ones who might become brilliant theorists, experimentalists, or clinicians, for example-might never be allowed to make their potential contributions because they receive neither the ability-test scores nor the grades that would enable them to enter the fast-track, or perhaps any track, to success in their chosen field (Sternberg, 1994). They may be forced to switch to a less challenging and rewarding field or to a less challenging and rewarding program within their chosen field, because they are denied the optimal access routes that would enable them to achieve the success they seek.

The same principle applies, of course, to careers other than psychology as well. In any field, low performance on narrow ability tests or in introductory courses that emphasize abilities that later will be largely irrelevant for excellence in the field can result in people being sidetracked and ultimately derailed from career success.

\section{Conclusion}

The view I take here is that our society needs a broad and principled understanding of just what is meant by intelligence and a principled way of determining just what criteria an ability must pass to be viewed as a part of intelligence. These steps will provide people the basis for understanding not only what intelligence is but what place it has in preparing for lifelong learning and success. I have proposed here a definition of intelligence that posits one set of such criteria for understanding intelligence: the mental abilities necessary for adaptation to, as well as shaping and selection of, any environmental context. This definition can lead us to a broader conceptualization of the role of intelligence in lifelong learning.

\section{REFERENCES}

Anderson, J. R. (1983). The architecture of cognition. Cambridge, MA Harvard University Press.

Baltes, P. B., Dittmann-Kohli, F., \& Dixon, R. A. (1984). New perspectives on the development of intelligence in adulthood: Toward a dualprocess conception and a model of selective optimization with compensation. In P. B. Baltes \& O. G. Brim, Jr. (Eds.), Life-span develop ment and behavior (Vol. 6, pp. 33-76). New York: Academic Press

Bandura, A. (1977). Self-efficacy: Toward a unifying theory of behavioral change. Psychological Review, 84, 181-215.

Barkow, J. H., Cosmides L., \& Tooby J. (1992). The adapted mind. New York: Oxford University Press.

Binet, A., \& Simon, T. (1916). The development of intelligence in children. Baltimore: Williams \& Wilson. (Original work published 1905)

Buss, D. M. (1995). Evolutionary psychology: A new paradigm for psychological science. Psychological Inquiry, 6, 1-30.

Campione, J. C., \& Brown A. L. (1990), Guided learning and transfer: Implications for approaches to assessment. In N. Frederiksen, R. Glaser, A. Lesgold, \& M. Shafto (Eds.), Diagnostic monitoring of skill and knowledge acquisition (pp. 141-172). Hillsdale, NJ Erlbaum.

Cantor, N., \& Kihlstrom, J. F. (1987). Social intelligence: The cognitive basis of personality. In P. Shaver (Ed.)., Review of personality and social psychology (Vol. 6, pp. 15-34). Beverly Hills, CA: Sage.

Carroll, J. B. (1993). Human cognitive abilities: A survey of factoranalytic studies. New York: Cambridge University Press.

Chi, M. T. H., Glaser, R., \& Farr, M. J. (Eds.). (1988). The nature of expertise. Hillsdale, $\mathrm{NJ}$ : Erlbaum. 
Cole, M., Gay, J., Glick, J., \& Sharp, D.W. (1971). The cultural context of learning and thinking. New York: Basic Books.

Estes, W. K. (1982). Models of leaming, memory and choice: Selected papers. New York: Praeger.

Ford, M. E., \& Tisak, M. S. (1983). A further search for social intelligence. Journal of Educational Psychology, 75, 197-206.

Gardner, H. (1983). Frames of mind: The theory of multiple intelligences. New York: Basic Books.

Gardner, H. (1993). Multiple intelligences: The theory in practice. New York: Basic Books.

Goleman, D. (1995). Emotional intelligence. New York: Bantam Books.

Heath, S. B. (1983). Ways with words. New York: Cambridge University Press.

Hebb, D. O. (1949). The organization of behavior. New York: Wiley.

Hegel, G. W. F. (1931). The phenomenology of mind (2nd ed.; J. B. Baillie, Trans.). London: Allen \& Unwin. (Original work published 1807)

Herrnstein, R. J., \& Murray, C. (1994). The bell curve: Intelligence and class structure in American life. New York: Free Press.

Horn, J. L. (1986). Intellectual ability concepts. In R. J. Sternberg (Ed.), Advances in the psychology of human intelligence (Vol. 3, pp. 3577). Hillsdale, NJ: Erlbaum.

Horn, J. L. (1994). Theory of fluid and crystallized intelligence. In R. J. Sternberg (Ed.), The encyclopedia of human intelligence (Vol. 1, pp. 443-451). New York: Macmillan.

Hunt, E. (1995). Will we be smart enough? A cognitive analysis of the coming workforce. New York: Russell Sage Foundation.

Intelligence and its measurement: A symposium. (1921). Journal of Educational Psychology, 12, 123-147, 195-216, 271-275.

Jerison, H. J. (1982). The evolution of biological intelligence. In R. J. Sternberg (Ed.)., Handbook of human intelligence (pp. 723-791). New York: Cambridge University Press.

Keating, D. P. (1978). A search for social intelligence. Journal of Educational Psychology, 70, 218-223.

Labouvie-Vief, G. (1982). Dynamic development and nature autonomy: A theoretical prologue. Human Development, 25, 161-191.

Lubart, T. I., \& Sternberg, R. J. (1995). An investment approach to creativity: Theory and data. In S. M. Smith, T. B. Ward, \& R. A. Finke (Eds.), The creative cognition approach (pp. 269-302). Cambridge, MA: MIT Press.

Mayer, J. D., \& Geher, G. (1996). Emotional intelligence and the identification of emotion. Intelligence, 22, 89-113.

McDermott, R. P. (1974). Achieving school failure: An anthropological approach to illiteracy and social stratification. In G. Spindler (Ed.), Education and the cultural process (pp. 82-118). New York: Holt, Rinehart \& Winston.

Neisser, U. (1979). The concept of intelligence. In R. J. Sternberg \& D. K. Detterman (Eds.), Human intelligence: Perspectives on its theory and measurement (pp. 179-189). Norwood, NJ: Ablex.

Neisser, U. (Ed.). (1982). Memory observed: Remembering in natural contexts. San Francisco: Freeman.

Okagaki, L., \& Sternberg, R. J. (1991). Cultural and parental influences on cognitive development. In L. Okagaki \& R. J. Sternberg (Eds.), Directors of development: Influences on the development of children's thinking (pp. 101-120). Hillsdale, NJ: Erlbaum.

Pascual-Leone, J. (1984). Attentional, dialectic, and mental effort. In M. L. Commons, F. A. Richards, \& C. Armon (Eds.), Beyond formal operations (pp. 182-215). New York: Plenum.

Pascual-Leone, J. (1987). Organismic processes for neo-Piagetian theories: A dialectical causal account of cognitive development. International Journal of Psychology, 22, 531-570.

Salovey, P., \& Mayer, J. D. (1990). Emotional intelligence. Imagination, Cognition, and Personality, 9, 185-211.

Salthouse, T. A. (1996). The processing-speed theory of adult age differences in cognition. Psychological Review, 103, 403-428.

Schmidt, F. L., \& Hunter, J. E. (1993). Tacit knowledge, practical intelligence, general mental ability, and job knowledge. Current Directions in Psychological Science, 1, 8-9.

Steele, C., \& Aronson, J. (1995). Stereotype threat and the intellectual test performance of African Americans. Journal of Personality and Social Psychology, 69, 797-812.

Sternberg, R. J. (1985a). Beyond IQ: A triarchic theory of human intelligence. New York: Cambridge University Press.

Sternberg, R. J. (1985b). Implicit theories of intelligence, creativity, and wisdom. Journal of Personality and Social Psychology, 49, 607 . 627.

Sternberg, R. J. (1988). The triarchic mind: A new theory of human intelligence. New York: Viking Press.

Sternberg, R. J. (1990). Metaphors of mind: Conceptions of the nature of intelligence. New York: Cambridge University Press.

Sternberg, R. J. (1993). Sternberg Triarchic Abilities Test. Unpublished test.

Sternberg, R. J. (1994). A triarchic model for teaching and assessing students in general psychology. General Psychologist, 30(2), 42-48.

Sternberg, R. J. (1995a). For whom the bell curve tolls: A review of The Bell Curve. Psychological Science, 6, 257-261.

Sternberg, R. J. (1995b). In search of the human mind. Ft. Worth, TX: Harcourt Brace.

Sternberg, R. J. (1996a). Myths, countermyths, and truths about intelligence. Educational Researcher, 25(2), 11-16.

Sternberg, R. J. (1996b). Successful intelligence. New York: Simon \& Schuster.

Sternberg, R. J. (1997). Educating intelligence: Infusing the triarchic theory into school instruction. In R. J. Sternberg \& E. L. Grigorenko (Eds.), Intelligence, heredity, and environment (pp. 343-362). New York: Cambridge University Press.

Sternberg, R. J., \& Clinkenbeard, P. (1995). A triarchic view of identifying, teaching, and assessing gifted children. Roeper Review, 17, $255-260$.

Sternberg, R. J., \& Detterman D. K. (Eds.). (1986). What is intelligence? Contemporary viewpoints on its nature and definition. Norwood, NJ: Ablex.

Sternberg, R. J., Ferrari, M., Clinkenbeard, P. R., \& Grigorenko, E. L. (1996). Identification, instruction, and assessment of gifted children: A construct validation of a triarchic model. Gifted Child Quarterly, $40,129-137$

Sternberg, R. J., \& Gardner, M. K. (1983). Unities in inductive reasoning. Joumal of Experimental Psychology: General, 112, 80-116.

Sternberg, R. J., \& Lubart, T. I. (1992). Buy low and sell high: An investment approach to creativity. Current Directions in Psychological Science, 1, 1-5.

Sternberg, R. J., \& Lubart, T. I. (1995). Defying the crowd: Cultivating creativity in a culture of conformity. New York: Free Press.

Sternberg, R. J., \& Lubart, T. I. (1996). Investing in creativity. American Psychologist, 51, 677-688.

Sternberg, R. J., \& Smith, C. (1985). Social intelligence and decoding skills in nonverbal communication. Social Cognition, 2, 168-192.

Sternberg, R. J., Torff, B., \& Grigorenko, E. L. (1997). Teaching triarchically improves school achievement. Manuscript submitted for publication.

Sternberg, R. J., \& Wagner, R. K. (Eds.). (1986). Practical intelligence: Nature and origins of competence in the everyday world. New York Cambridge University Press.

Sternberg, R. J., \& Wagner, R. K. (1993). The g-ocentric view of intelligence and job performance is wrong. Current Directions in Psychological Science, 2, 1-5.

Sternberg, R. J., Wagner, R. K., \& Okagaki, L. (1993). Practical intelligence: The nature and role of tacit knowledge in work and at school. In H. Reese \& J. Puckett (Eds.), Advances in lifespan development (pp. 205-227). Hillsdale, NJ: Erlbaum.

Sternberg, R. J., Wagner, R. K., Williams, W. M., \& Horvath, J. A. (1995). Testing common sense. American Psychologist, 50, $912-$ 927.

Sternberg, R. J., \& Williams, W. M. (1997). Does the GRE predict meaningful success in the graduate training of psychologists? A case study. American Psychologist, 52, 630-641.

Wechsler, D. (1939). The measurement of adult intelligence. Baltimore: Williams \& Wilkins.

Wechsler, D. (1958). The measurement and appraisal of adult intelligence (5th ed.). Baltimore: Williams \& Wilkins.

Wright, R. (1994). The moral animal. New York: Vintage. 